\title{
Gastric outlet obstruction due to gall stones (Bouveret syndrome)
}

\author{
K. Ah-Chong ${ }^{1}$ and Y.P. Leong ${ }^{2}$ \\ ${ }^{1}$ Derbyshire Royal Infirmary, London Road, Derby DE1 2QY and ${ }^{2}$ Derby City Hospital, Uttoxeter Road, Derby \\ DE3 $3 N E, U K$.
}

\begin{abstract}
Summary: Gastric outlet obstruction by gall stone is a rare complication of a common disorder. Two cases are reported here. The investigations are conducted along the same lines as for pyloric stenosis. The diagnosis can be made with a barium meal or gastroscopy. Treatment is by surgical intervention after adequate resuscitation.
\end{abstract}

\section{Introduction}

Gall stone ileus complicates $0.3 \%$ to $0.5 \%$ of all cases of cholelithiasis. ' The commonest site is in the terminal ileum. Duodenal obstruction is rare and occurs in less than $3 \%$ of patients with gall stone ileus. ${ }^{2}$ We report two cases.

\section{Case reports}

\section{Case 1}

A 60 year old woman was admitted with a one month history of anorexia, vomiting and abdominal pain. She had had a similar episode 4 months previously, which resolved after treatment with antacids. Examination revealed a grossly obese dehydrated woman $(180 \mathrm{~kg})$. She was tender in the epigastrium and a succussion splash was elicited.

Investigations showed hypokalaemia $(2.4 \mathrm{mmol} / \mathrm{l})$ and a high blood urea $(35.9 \mathrm{mmol} / 1)$. Barium meal showed a deformed duodenal cap with a large filling defect and a cholecystoduodenal fistula (Figure 1). Endoscopy demonstrated an impacted gall stone in the first part of the duodenum.

At laparotomy the stone was extracted through a pylorotomy which revealed a wide cholecystoduodenal fistula. The anatomy of the common bile duct was greatly distorted so a cholecystotomy was performed leaving a Foley catheter in the fibrotic gall bladder. The stone was $8 \mathrm{~cm}$ long. She remains well 6 months after the operation.

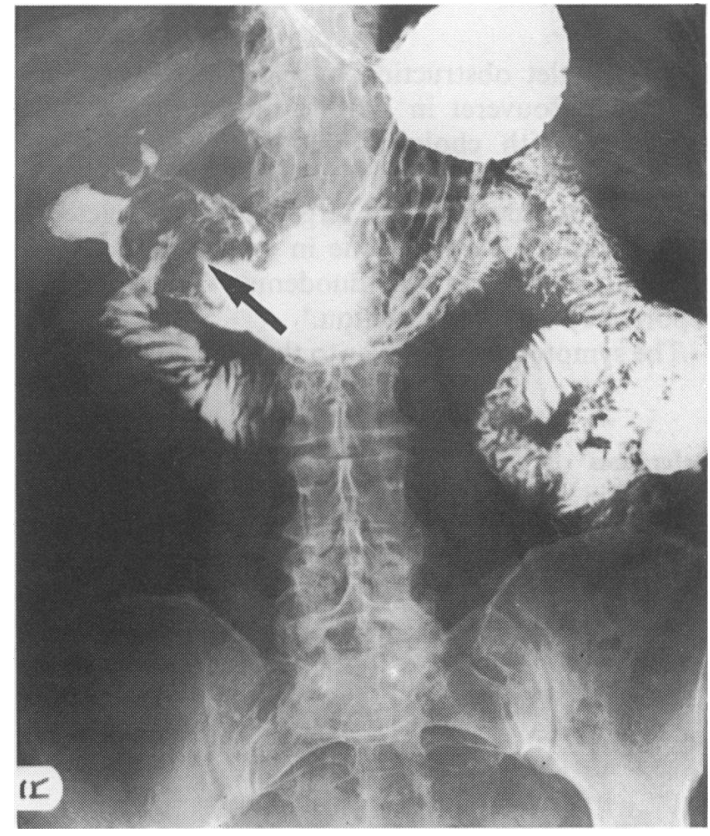

Figure 1 Barium meal demonstrated a large gall stone in the first part of the duodenum and a cholecystoduodenal fistula.

\section{Case 2}

An 84 year old man developed epigastric pain and repeated profuse vomiting. Three months previously he had had a similar episode, which resolved spontaneously. On examination the patient was dehydrated, and the abdomen was distended. He was tender in the epigastrium and there was a succussion splash.

(C) The Fellowship of Postgraduate Medicine, 1987 
Investigations revealed a high urea $(17.0 \mathrm{mmol} / \mathrm{l})$ and a slightly raised alkaline phosphatase (431 IU/1) but were otherwise normal. Barium meal suggested a large gall stone impacted in the duodenal cap. Endoscopy confirmed the presence of a gall stone, but the attempted endoscopic manipulation proved unsuccessful.

At laparotomy the gall bladder and duodenum were separated through dense fibrous tissue, leaving a hole in the duodenum $4 \mathrm{~cm}$ in diameter, through which the black gall stone was visible. The stone was tightly impacted in the duodenal bulb. In order to remove it, it was necessary to enlarge the fistula by incising the duodenum proximally towards the pyloric ring. After extracting the stone the duodenotomy was closed transversely, and a cholecystectomy was performed. The stone was $7 \frac{1}{2} \mathrm{~cm}$ long. He remained well 6 months post-operatively.

\section{Discussion}

Gastric outlet obstruction by gall stones, first described by Bouveret in 1896 is rare, and is usually associated with cholecystoduodenal fistula, which accounts for $77 \%$ of biliary enteric fistulae. ${ }^{3}$ The obstruction occurs when a large stone is impacted in the duodenum. A gall stone in the intramural submucosal portion of the duodenum has also been reported to cause obstruction. ${ }^{4}$

The symptoms are similar to those of peptic ulcera-

\section{References}

1. Middleton, M.D. \& Muscroft, T.J. Duodenal obstruction due to gall stone. $J R$ Coll Surg Edinb 1980, 25: 41-43.

2. Day, E.A. \& Mark, C. Gall stone ileus. Am J Surg 1975, 129: 552-558.

3. Glenn, F., Reed, C. \& Grafe, W.R. Biliary enteric fistula tion, pyloric carcinoma, duodenal neoplasm, polyp, foreign body and pressure from extramural mass. In a series of 34 patients, 21 gave no previous history suggestive of cholelithiasis. ${ }^{2}$ Gas in the biliary tract is a helpful radiological sign, but it occurs in only $29 \%$ of cases. ${ }^{5}$ However, an accurate diagnosis should not be difficult if this condition is borne in mind. A barium meal is useful, as it may show the typical filling defect and the fistula. When there is doubt, gastroduodenoscopy will confirm the diagnosis. Endoscopic removal is often impossible as the large size of the impacted gall stone precludes any successful manipulation. Treatment aims at relieving the obstruction by removing the gall stones. If the patient is ill, or the anatomy is so distorted, it may be necessary to postpone definitive treatment by cholecystectomy and closure of the fistula, which may become hazardous in an emergency situation (Case 1). An elective procedure may be performed at a later date if indicated, under more favourable circumstances.

With the advance of technology, an endoscopic lithotripter may be available in the future which can be used to shatter the impacted stone so as to relieve the obstruction. This will be particularly useful in elderly patients in poor general condition.

\section{Acknowledgements}

We are grateful to $\mathrm{Mr}$ P. Goodall and Mr W.A. Anderson fơ their advice and the permission to report on their patients.

Surg Gynaecol Obstet 1981, 153: 527-531.

4. Margolis, J.L. et al. RI Medical Journal 1984, 67: 33-34,

5. Simonian, S.J. Gall stone obstruction of the duodenal. bulb. Lancet 1968, i: 893-894. 